\title{
AUTOMATING INDUSTRIAL TASKS THROUGH MECHATRONIC SYSTEMS - A REVIEW OF ROBOTICS IN INDUSTRIAL PERSPECTIVE
}

\author{
Jamshed Iqbal, Raza Ul Islam, Syed Zain Abbas, Abdul Attayyab Khan, Syed Ali Ajwad
}

Subject review

Pressing requirements of improved and enhanced productivity in industrial applications has necessitated deployment of robot to automate tasks. Manipulator based articulated robots for today's industrial applications vary widely in terms of number of Degree Of Freedom (DOF), payload capacity, Range Of Motion (ROM), control implementation and mountable configurations. This paper presents a comprehensive and systematic review of industrial robots with a focus on their application areas. The study of manipulators for diversified applications has highlighted the need of sophisticated algorithms for their control and trajectory planning. Both of these key concepts are discussed in the paper. The control of industrial manipulator is important for accomplishing tasks requiring high precision, repeatability and reliability by mitigating the effects of disturbances. The trajectory planning is vital for time optimization, energy optimization and collision avoidance to ensure most appropriate trajectory for a given task in an environment. The application oriented review offers readers opportunities to generate ideas applicable to their operations and to conform feasibility of their ideas.

Keywords: industrial automation; robot control; robotic manipulators; trajectory planning

\section{Automatzacija industrijskih poslova kroz mehatroničke sustave - pregled robotike iz industrijske perspektive}

Pregledni članak

Sve veći zahtjevi za poboljšanom i povećanom produktivnošću u industriji doveli su do potrebe razvoja robota u automatizaciji poslova. Zglobno vezani roboti bazirani na manipulatoru za sadašnje industrijske aplikacije uvelike variraju u odnosu na broj stupnja slobode -Degree Of Freedom (DOF), kapacitet nosivosti, raspon pokreta - Range Of Motion (ROM), provođenje kontrole i ugradnju konfiguracija. U radu se daje opsežan i sustavan pregled industrijskih robota s naglaskom na njihova područja primjene. Analiza manipulatora za različite primjene istaknula je potrebu za složenim algoritmima za njihovo upravljanje i planiranje putanje. O ovim se ključnim pitanjima raspravlja u radu. Kontrola industrijskog manipulatora je važna za obavljanje zadataka za koje je potrebna velika preciznost, ponavljanje i pouzdanost uz izbjegavanje smetnji. Planiranje putanje je od bitne važnosti za optimizaciju vremena, optimizaciju energije i izbjegavanje sudara kako bi se osigurala najprihvatljivija putanja za određeni zadatak u nekom okruženju. Pregled literature usmjeren na primjenu pruža čitateljima mogućnost da razviju ideje koje se mogu primijeniti na njihove poslove i razmisle o izvedivosti svojih ideja.

Ključne riječi: industrijska automatizacija; manipulatori robotima; planiranje putanje; upravljanje robota

\section{Introduction}

Developments in research have brought the technologies of automation and robotics very close to each other [1]. In an industrial perspective, automation deals with electrical/electronic, mechanical and computerbased solutions to operate and control the production process. In view of that, robotics lies in the category of industrial automation. An industrial robot, as defined by Robotics Industries Association (RIA), is "a reprogrammable, multifunctional manipulator designed to move material, parts, tools, or special devices through variable programmed motions for the performance of a variety of tasks" [2]. Today, robots are highly automated mechanical manipulators controlled by computers. Recent demand to maximize productivity in the industrial sector has necessitated employing the robots to accomplish various tasks in an autonomous or semi-autonomous fashion [3]. Robots are now considered as an integral part of industries due to their role in improving accuracy, repeatability, reliability, preciseness and efficiency. As industries have become a key factor for economic progress of any country and are essential to fulfill the needs of people, industrial robots have replaced a wide range of human tasks, since they are free from a lot of problems which humans are bound to have. They do not have fear, tiredness, and lack of interest or any other such factor which could be a constraint in achieving targets. Presence of robots decreases chances of mistake which itself is a sufficient security measure. These factors have highlighted the potential of robots in industries.
Automation of industries is primarily based on human arm-like robots. Articulated arms, comprised of revolute joints, are commonly utilized in manufacturing lines because of their multi-directional movement flexibility.

The primary challenging subjects of utmost interest related with industrial manipulators include Control systems, Trajectory planning, Mechanical design and Computer vision. The task accomplishment by a manipulator involves its movement that is caused by an applied force/torque provided by a single or multiple actuators. The main objective of control is to generate appropriate commands for actuator to position and orient the wrist and tool with desired precision and speed. The overall control problem consists of (i) derivation of manipulator's dynamics and (ii) determination of control laws to meet required performance criteria. The solution to the control problem gets more complicated by coupling reaction forces, inertial forces and gravity loading on the links. The second aspect of manipulator control is trajectory tracking which is concerned with the design of laws to force a manipulator follow a predefined sequence of points in space. The complexity of this problem is a strong function of the manipulator configuration. The trajectory planner incorporates obstacle constraints as well as path constraint.

The present work presents a comprehensive review of various industrial robots in context of their applications. Of the four challenging subjects listed above, the first two aspects; control and trajectory planning are discussed. The review can be a good resource to select a robotic manipulator as per requirements in addition to enhancing 
the understanding of the robots in industries. For engineering students, this systematic review can act as a good source of motivation to conduct research in the allied areas. Because of versatility of related fields in the development of industrial manipulators, this state-of-theart can bridge the gap between theoretical academic knowledge and practical industrial requirements. For professionals, this article is anticipated to serve as a reference while designing similar systems.

This review is based on the authors' over a decade experience of realizing novel robotic devices $[4 \div 11]$, conceiving didactic robotic frameworks [12-14], proposing modeling $[15 \div 18]$ and optimization strategies [19] and other highly efficient algorithms for various robot's categories $[20 \div 29]$. An autonomous image-guided robotic system simulating industrial applications is proposed by Raza et al. [30]. The system has been realized by combining the robot kinematics and image processing to simulate wide range of common industrial tasks. Using the system, Iqbal et al. practically demonstrated pick and place task [15]. AUTonomous Articulated Robotic Educational Platform (AUTAREP) presented by researchers at CIIT, Pakistan, is an opensource platform centred on a 6 Degree Of Freedom (DOF) arm with an on-board camera [31]. The platform has a great potential for preparing engineers and researchers for industry. In an industrial sector, the platform can be used to validate the planned trajectories prior to actual execution. Figure 1 illustrates the platform executing the industrial task of autonomous object sorting on the basis of shape, size and colour. Objects with varying attributes have been placed inside the robot's workspace, which is scanned by the camera. Based on user's selected sorting criteria, the centre point coordinate(s) of object(s) of interest are determined using image processing. The derived Inverse Kinematic model of the robot then gives the required position and orientation so as to pick/place the desired object(s).

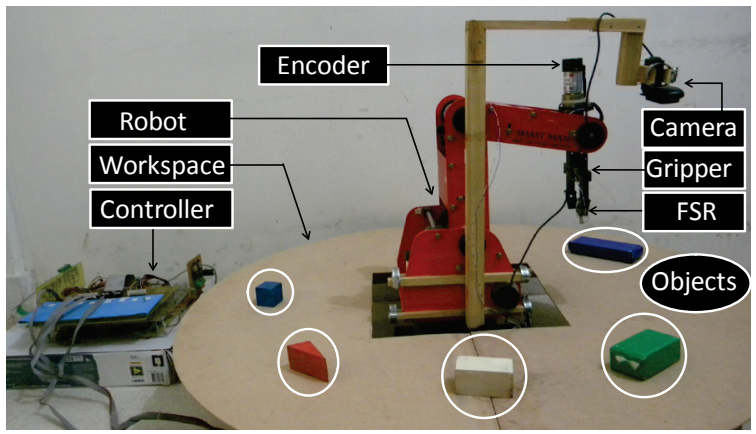

Figure 1 AUTAREP performing object sorting operation [12]

A graphical simulation of industrial robotized sites using SolidWorks ${ }^{\mathrm{TM}}$ Application Programming Interface (API) is presented in [32]. The proposed strategy is primarily based on the developed 3D model of the site and time optimization guaranteeing collision avoidance and accessibility [33]. A typical industrial example is illustrated in Fig. 2 where Staubli robot RX-130 XL is performing spot-welding task in an automation plant.

The rest of the paper is organized as follows: Initially, categorized applications of industrial manipulators are detailed. Then their control is discussed followed by description of recent advances in trajectory planning strategies. Finally, conclusion is presented.

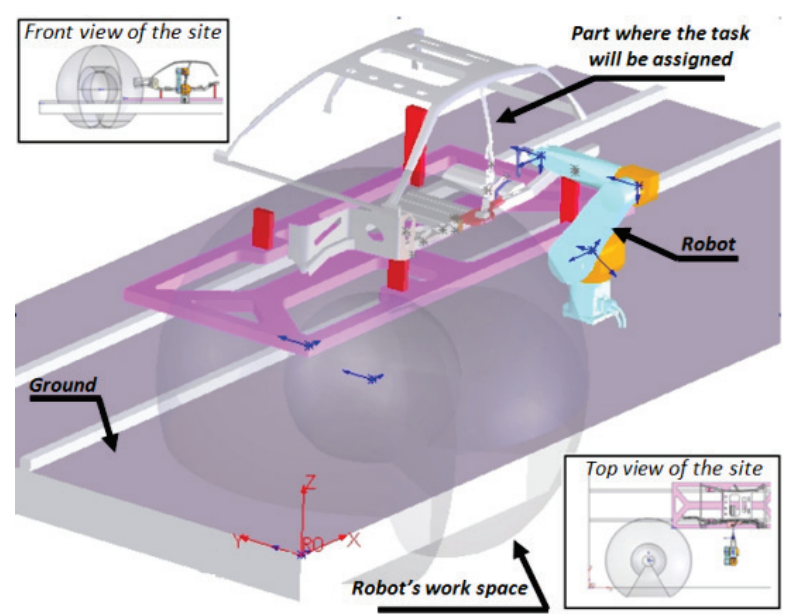

Figure 2 An example of robotized automation site with the robot for spot-welding [33]

\section{Applications of industrial manipulators}

Current-day robot applications include a wide variety of production operations in an industrial sector. These application tasks can be welding [34], assembly [35], paint spraying [36], packaging and arranging [37], cutting [38], moving [39], sanding [40] and much more. The first three applications being the most common ones are detailed below:

\subsection{Welding}

Welding is the first application of industrial robots as of the early 1990s [41]. This application is most commonly found as spot welding in heavy assembly-line industries such as automobile and truck manufacturing, but arc-welding robots are on the increase. The benefits offered by robot deployment compared to traditional manual welding include improved superior quality and uniformity, better hazardous safety and quality-of-work life, enhanced quality of product and process rationalization.

$\mathrm{ABB}$ robotics is considered as pioneer in designing industrial manipulators. IRB 7600 [42] illustrated in Fig. $3 \mathrm{a}$ is one such robust robot model designed for spot welding and arc welding. The manipulator features better tracking precision $( \pm 0,05 \mathrm{~mm})$ and low power consumption for high speed operations. The arm is mountable on a shelf or on a wall in tilted or inverted configuration. ABB provides separate software solutions for both types of welding. COMAU offers advance robotic manipulators featuring high flexibility, precision and throughput for industrial sector [43]. The robots intended for welding vary significantly in terms of payload capacity and reachability e.g. SMART Arc 4 can handle payloads of $5 \mathrm{~kg}$ while the capacity for Smart5 NJ4 (Fig. 3b) is $270 \mathrm{~kg}$. The robots can be positioned on floor or in ceiling position. The custom-developed control unit $\mathrm{C} 4 \mathrm{G}$ offers high speed and optimal performance laser welding solution.

A joint venture of Panasonic Welding Co. and Miller Electric Manufacturing Co. resulted in compact solutions 
with extended reachability for high speed arc welding automation. TA series manipulators [44] together with the developed 64-bit G2 controller offer an ideal combination for automated welding. The novel wrist axis design and curved arm permit less interference to the manipulator itself. The flexible controllable manipulator, actuated with AC servo motors, is also equipped with sensitive collision guard function, arc and touch sensors.

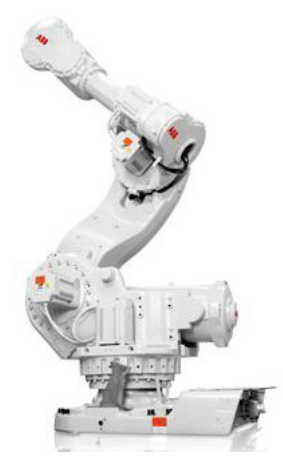

(a)

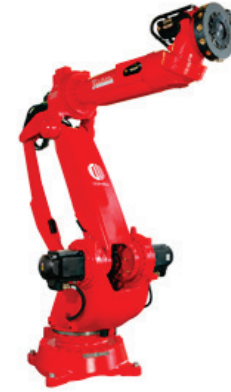

(b)
Figure 3 Manipulators for welding (a) IRB 7600 and (b) Smart5 NJ4

\subsection{Assembly}

The most challenging arena for robot applications is robotic assembly. Assembly demands repeatability, precision, variety of motion, sophisticated gripper devices and sometimes compound gripper mechanisms in which the gripper plays an active and primary role in one of the assembly steps, besides simply holding pieces of the parts. The benefits offered by robots in assembling include saving labour cost and accomplishing task with robustness, efficiency and accuracy [41]. The robots used in assembly line to augment productivity with high consistency can find potential in material and component handling. Popular examples include engine assembly and electrical/electronic machine assembly.

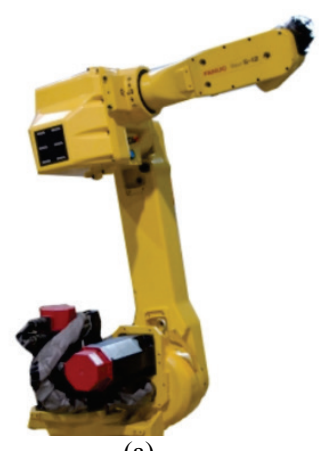

(a)

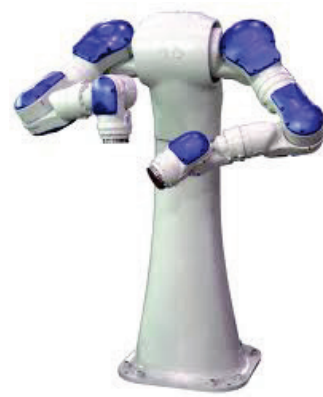

(b)
Figure 4 Manipulators for assembling (a) Fanuc S-12 and (b) SDA10D

FANUC S-12 [45], shown in Fig. 4a, is a directdriven double-jointed arm actuated with brushless DC servo motors. With a repeatability of $\pm 0,1 \mathrm{~mm}$, the robot exhibits rigid design and low arm mass that permits precise positioning at high speeds. The robot is mountable in upright, angle or inverted position and can also be positioned on a shelf or a wall without any modification. SDA10D (Fig. 4b) by YaskawaMotoman is a dual-arm specially designed for assembly line and material handling [46]. It is a 15 -axis robot where both arms can function independently as well as jointly thus doubling the payload. The actuation is based on electric servos while a custom-developed module DX100 controls the robot. Adept Viper series [47] is also specifically designed for assembly applications. The high-resolution encoders of the robot together with the repeatability of $\pm 0,020 \mathrm{~mm}$ and allowable torque of $5,9 \mathrm{~N} \cdot \mathrm{m}$ makes the robot ideal for packaging, material handling and machine tending operations.

\subsection{Painting}

This process involves use of spray guns to apply the paint or other coating to the object. The traditional air spray uses compressed air mixed with the paint to atomize it into a high velocity stream which is then directed through a nozzle. The benefits offered by robots in spray coating include removal of operators from hazardous environment, consistency of finish, lower energy consumption, greater productivity and reduced coating material usage [2].

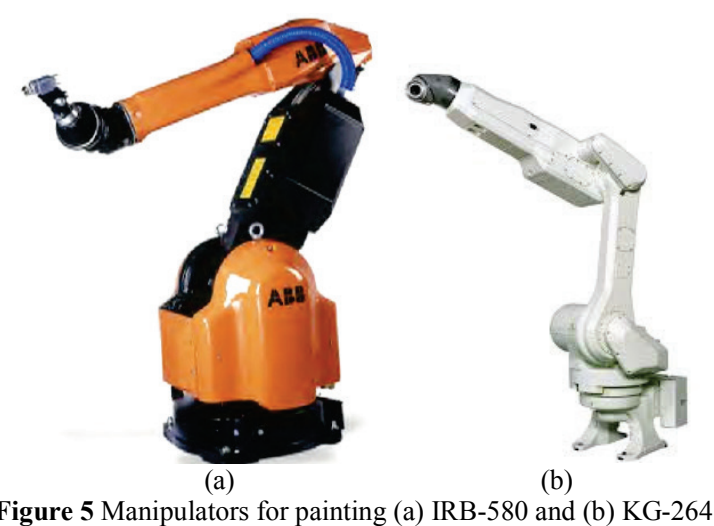

Figure 5 Manipulators for painting (a) IRB-580 and (b) KG-264

ABB's IRB-580 [48] illustrated in Fig. 5a, is a 6-axis manipulator designed for spray painting. Actuated with AC servo motors, promising features of the robot include symmetrical and counter balanced design. $140^{\circ}$ ROM in wrist rotation offers versatility and ease of programming. The precise hollow wrist design permits elimination of wear and tear on the hoses to increase overall reliability. The designed controller maintains the desired air flow and paints at high speed using closed loop regulation. Developed Analog Paint Regulation (APR) System reduces paint consumption ultimately reducing the material cost. Synchronizing the robot motion with the paint process and integrating equipment as per painting application requirements has helped to lessen material wastage and to improve response time. KG264 [49] (Fig. $5 b)$ is another hollow wrist 6-axes explosion-proof industrial robot developed and marketed by Kawasaki robots. The robot can be programmed via teaching pendant or with two programming languages; block step and AS language. Time consumption is optimized through auto path generating software that is designed in block step while flexibility in programming to design advanced logics for controlling the paint process is offered by AS language. The provided interface displays ongoing status of coating process, production and error.

The technical specifications of above mentioned applications are listed in Tab.1. Besides these main applications, robotics companies e.g. KUKA and 
Motoman have presented a number of solutions for other industrial applications including machine loading, laser cutting, inspection, pick and place, palletizing, moulding, die casting and packing. Tab.2 presents popular robots marketed by these two companies.

Table 1Popular robots for common industrial applications

\begin{tabular}{|c|c|c|c|c|c|c|}
\hline Application & Company & Model & DOF & Weight (kg) & Payload (kg) & Max. reach $(\mathrm{m})$ \\
\hline \multirow{2}{*}{ Welding } & $\mathrm{ABB}$ & IRB-7600 & 6 & 2550 & $150 \div 500$ & $2,55 \div 3,50$ \\
\hline & Miller/Panasonic & TA 1900 & 6 & 185 & 6 & 1,895 \\
\hline \multirow[t]{2}{*}{ Assembling } & MOTOMAN & Yaskawa SDA10D & 15 & 220 & 10/arm & $1,97(\mathrm{H}), 1,44(\mathrm{~V})$ \\
\hline & ADEPT & Adept Viper & 6 & 28 & $2,5-5$ & $0,653 \div 1,298$ \\
\hline Painting & $\mathrm{ABB}$ & IRB-580 & $6 \div 7$ & 630 & 10 & $2,18 / 2,56$ \\
\hline
\end{tabular}

Table 2Popular industrial robots developed by KUKA and Motoman

\begin{tabular}{|c|c|c|c|c|c|}
\hline Company & Model & DOF & Weight $(\mathrm{kg})$ & Payload (kg) & Max reach $(\mathrm{m})$ \\
\hline \multirow{5}{*}{ KUKA } & KR 40 PA & \multirow{2}{*}{4} & 700 & 40 & 2,091 \\
\hline & KR 700 PA & & 2850 & 700 & 3,320 \\
\hline & KR 180 R3200 PA & \multirow{2}{*}{5} & 1093 & 180 & 3,195 \\
\hline & KR 300-2 PA & & 2150 & 300 & 3,150 \\
\hline & KR 2000 Series & 6 & 1300 & $150 \div 210$ & $2,7 \div 3,1$ \\
\hline \multirow{4}{*}{ Motoman } & MPP3 & 4 & 115 & 3 & 1,3 \\
\hline & MPL series & $4 \div 5$ & $550 \div 2550$ & $80 \div 800$ & $2,061 \div 3,159$ \\
\hline & MPL80 & 5 & 550 & 80 & 2,061 (H), 3,291 (V) \\
\hline & EPH Series & 6 & $1445 \div 3050$ & $100 \div 200$ & $\begin{array}{l}2,651 \div 3,505(\mathrm{H}) \\
2,629 \div 4,151(\mathrm{~V})\end{array}$ \\
\hline
\end{tabular}

\section{Control of Industrial manipulators}

Successful implementation of robotics in the mentioned applications is obviously a function of proper control law $[50,51]$. The primary objective of control for continuous process variables is to apply a measured corrective action to compensate for variations from the reference level. A properly designed law tends to mitigate the effect of disturbances thus causing a process variable to follow exactly or nearly close to the desired level.

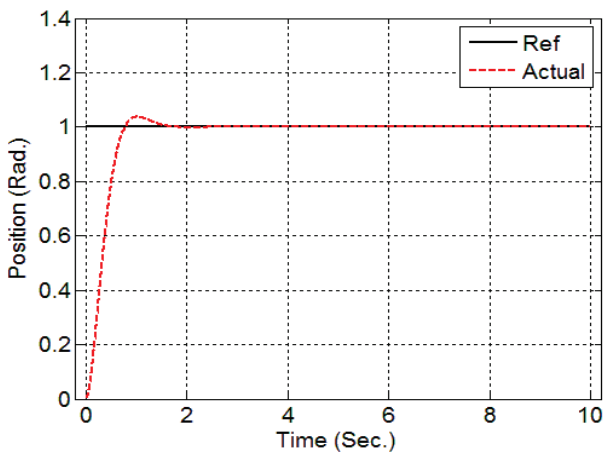

(a)

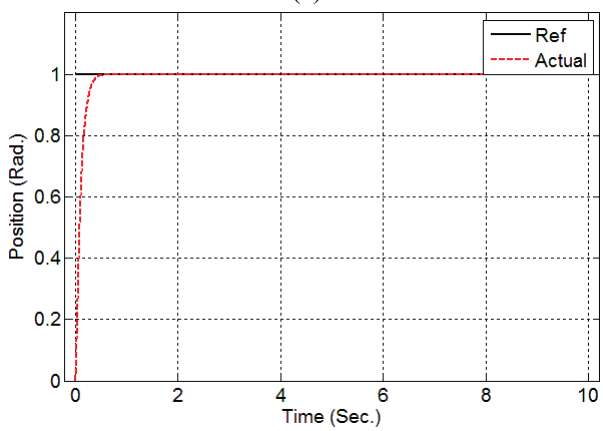

(b)

Figure 6 Performance comparison of a trivial and modern control strategy (a) PID and (b) SMC
The most fundamental control scheme is to apply correction to a process variable as soon as any error is encountered and to make the correction proportional to the magnitude of error. Getting cumulative data on the error i.e. error integration improves the steady state response. Further adding rate of change in error i.e. error derivative can help to damp overshoot. A ProportionalIntegral-Derivative (PID) control characterizes significant advancement in controls industry and is considered as main workhorse of process industry. It can be realized practically using components like Programmable Logic Controller (PLC) [52] or microcontrollers. Literature reports various methods to tune PID controllers [53]. These include Ziegler-Nichols open/closed loop, Lambda tuning, Cohen-Coon, Integral of Time weighted Absolute Error (ITAE)-Load etc. Recent research highlights tuning based on model switching adaptation [54]. Industrial applications of PID are reported in [55]. Most often, in these applications, the simple PID control is modified to improve the speed of recovery from process saturation scenarios commonly encountered [54]. The modification in PID control can be done by changing parameters, improving measurement or cascading multiple controllers.

The primary limitation of PID control is its nature of being a constant gain feedback system without having direct knowledge of the plant thus compromising the overall performance. Also, the linear and symmetric behavior of PID control law deteriorates the performance in case of controlling the industrial robots since the processes in industry exhibit nonlinear dynamics, unmeasured disturbances, resolution and sensitivity limits, measurement delays and lags, valve non-idealities and nonlinearities. Together with the demanding industrial applications of the present era, the limitations in trivial control approaches necessitate implementation of sophisticated laws to ensure robustness. Literature reports various modern control strategies including Computed 
Torque Control (CTC), Sliding Mode Control (SMC), Disturbance Observer Based Control (DOBC), Model Predictive Control (MPC), Linear Quadratic Regulator (LQR), $\mathrm{H}_{\infty}$ control and Passivity Based Control (PBC). The detail of most common control techniques is reported in [51].

Considering a pseudo-industrial robotic arm presented in Fig. 1, Fig. 6a and $6 \mathrm{~b}$ shows the response of wrist pitch joint using PID and SMC control respectively. The over performance of SMC is clearly evident from the response.

In the category of robust control design SMC and its derivatives have been widely researched. It is also termed as Variable Structure Control (VSC) because it can switch from one phase to another depending upon the system's current position. In SMC, a system is stabilized through modeled uncertainties and imprecisions along with the nonlinear feedback. The switching surface over which the error is derived has invariance to disturbances and uncertainties. A lot of work on SMC and its derivatives including Higher Order SMC (HOSMC), Integral SMC (ISMC) and Terminal SMC (TSMC) have been reported in research community. Integral sliding surface with adaptive law for switching function is proposed in [58] to compensate for uncertain parameters. SMC for PUMA560 robotic manipulator is reported by Piltanet al. [57]. Mahayana et al. [58] presented chattering free VSC controller using the adaptive gains hence approximating unknown system parameters. Feed forward control along with VSC to improve tracking performance is proposed in [59]. SMC involves two phases: (a) Starting from nonzero initial state, system reaches the sliding surface (b) As the system reaches the sliding surface, it remains on it for the future time. The control formulation follows the following steps: Initially, the sliding surface is defined. In case of a typical robotic manipulator, the second order system representing a sliding surface is given by (1).

$s=x_{2}+\lambda x_{1}$

In the next step, the equivalent control equation $u_{e q}$ is derived. The solution is obtained by taking the derivative of (1) untill the control input appears. The equation derived for $\dot{s}=0$ i.e. the desired objective can then be written as (2).

$u_{e q}=M\left(x_{1}\right)\left(\ddot{x}_{d}-\lambda\left(\dot{x}-x_{d}\right)\right)+V\left(x_{1}, x_{2}\right)+G\left(x_{1}\right)$

where $M\left(x_{1}\right)$ is the inertia matrix, $V\left(x_{1}, x_{2}\right)$ represents the centrifugal and corollis forces and $G\left(x_{1}\right)$ is the gravity matrix. (2) satisfies the condition $\dot{s}=0$, but it does not ensure that the sliding mode is established i.e. $s=0$. This will lead towards uncertanities and disturbances. That is why $u_{\text {dis }}$ is designed in a way so as to nullify the disturbance effects and retains $s=0$. The resulting equation for $u_{d i s}[50]$ is given by (3).

$u_{\text {dis }}=-k \operatorname{sign}(s)$

Using (2) and (3), the overall control law thus becomes (4).
$u=M\left(x_{1}\right)\left(\ddot{x}_{d}-\lambda\left(\dot{x}-x_{d}\right)\right)+V\left(x_{1}, x_{2}\right)+G\left(x_{1}\right)-k \operatorname{sign}(s)$

Typical block diagram of SMC for a robotic manipulator is given in Fig. 7. In addition to robust control, adaptive control is another recent category to control the robots. Its main advantage is that the controller changes its parameters to compensate time varying behavior of the system. [60] reports industrial implementation of adaptive fuzzy control for unknown parameters estimation and to compensate nonlinearities in the manipulator. Trivial control techniques like PID or its variants can also be combined with adaptive techniques to control a manipulator [61].

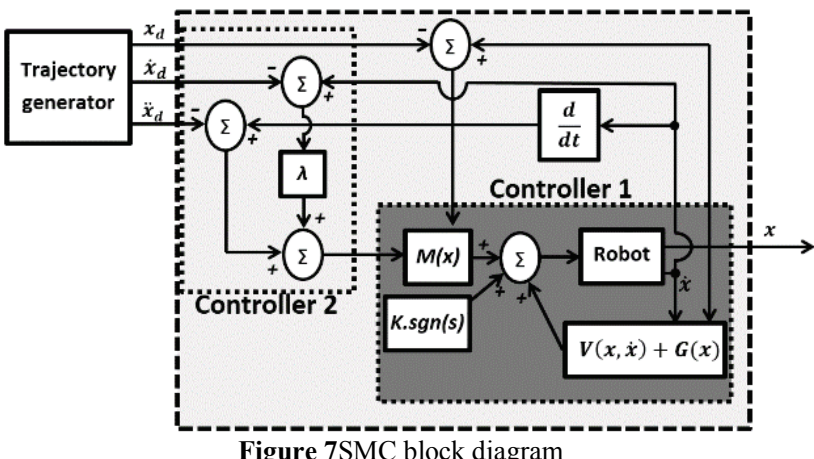

\section{Trajectory planning of industrial manipulators}

For successful task accomplishment, industrial manipulators usually require accounting for temporal information i.e. time history of position, velocity and acceleration for each DOF of the manipulator. The required trajectory to be followed can be point to point or continuous. Trajectory planning has to focus three main points i.e. time optimization, energy optimization and collision avoidance. So, the resultant motion pattern of the manipulator is less time consuming, smooth, jerk less and safe. The trajectory can be planned in Joint space or Cartesian space using the kinematic model of the robot. A typical solution of trajectory planning is illustrated in Fig. 8 [62].

Generally, geometric path and kinematic and dynamic constraints are input to any trajectory planning algorithm while its output is joint trajectories expressed as a time sequence of position, velocity and acceleration values. Literature reports various algorithms for trajectory planning. Examples include minimum seeking algorithms, genetic algorithms, spline-based algorithms and multiple objective optimization. Minimum seeking algorithms, designed to search the cost surface to minimize the height, can be based on exhaustive search, analytical optimization, Nedler-Mead downhill simplex method or line minimization. Genetic algorithms [32] work on the basis of genetics and natural selection and are well suited for parallel computers with an ability to optimize large number of continuous or discrete variables. Spline-based algorithms randomly select a sequence of points along the original path followed by construction of spline (e.g. cubic B type) to interpolate these points. Multiple objective optimizations can be based on weighted cost functions or Pareto optimization. The former method 
simply assigns weights to different functions and then adds them together while the later approach, also named as non-inferior solutions or effective solutions, attempts to determine optimal solution of trajectory planning problem. Recent trend is to combine these algorithms with other techniques to achieve better and precise results.

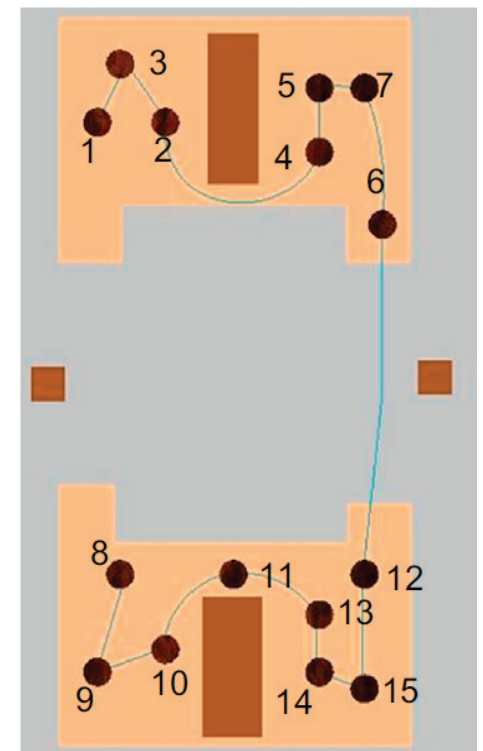

Figure 8 Solution tour of the manipulator's tip [62]

\section{Conclusion}

A detailed survey of existing industrial manipulators categorized in applications is presented with notes on the manipulator's control and trajectory planning. It is a myth that the area of industrial robotics is already saturated. We can expect much more developments in future. Sophisticated control algorithms together with fusion of sensors and learning capabilities will offer intuitive and user-friendly installation, maintenance and programming of industrial manipulators. The productivity can be further increased by employing hybrid vision-based and forcebased control. Enriching the capabilities of robots by using wireless communication is already under investigation. Moreover it is anticipated that future industrial robots will be much safer. In addition to industrial sector, manipulator based robots may find applications outside industrial plants in banks, restaurants or even at homes.

\section{References}

[1] Robert, J. S. Fundamentals of robotics: Analysis and control. Prentice Hall, Fourth impression, 2009.

[2] Groover, M. P.; Weiss, M.; Nagel, R. N.; Odrey, N. G. Industrial Robotics, Technology, Programming and Applications. Tata McGraw-Hill Edition, 2008.

[3] Asfahl, C. Robots and manufacturing automation. John Wiley \& Sons, Inc., 1992.

[4] Iqbal, J.; Khan, A. H.; Tsagarakis, N. G.; Caldwell, D. G. A novel exoskeleton robotic system for hand rehabilitation Conceptualization to prototyping. // Biocybernetics and Biomedical Engineering. 34, 2 (2014), pp. 79-89. DOl: 10.1016/j.bbe.2014.01.003

[5] Iqbal, J.; Tsagarakis, N. G.; Caldwell, D. G. Human hand compatible underactuated exoskeleton robotic system. //
IET Electronic Letters. 50, 7(2014), pp. 494-496. DOI: 10.1049/el.2014.0508

[6] Iqbal, J.; Tsagarakis, N. G.; Caldwell, D. G. A multi-DOF robotic exoskeleton interface for hand motion assistance. // $33^{\text {rd }}$ annual IEEE international conference of Engineering in Medicine and Biology Society / Boston, USA, 2011, pp. $1575-1678$.

[7] Iqbal, J.; Tsagarakis, N. G.; Caldwell, D. G. Design of a wearable direct-driven optimized hand exoskeleton device. $/ / 4^{\text {th }}$ International Conference on Advances in ComputerHuman Interactions / Guadeloupe, France, 2011, pp. 142146.

[8] Iqbal, J.; Ahmad, O.; Malik, A. HEXOSYS II - Towards realization of light mass robotics for the hand. $/ / 15^{\text {th }}$ IEEE International Multitopic Conference / Karachi, Pakistan, 2011, pp. 115-119. DOI: 10.1109/inmic.2011.6151454

[9] Iqbal, J.; Tsagarakis, N. G.; Fiorilla, A. E.; Caldwell, D. G. A portable rehabilitation device for the hand. // 32nd annual IEEE international conference of Engineering in Medicine and Biology Society / Buenos Aires, Argentina, 2010, pp. 3694-3697.

[10] Iqbal, J.; Tsagarakis, N. G.; Caldwell, D. G. A human hand compatible optimised exoskeleton system. // IEEE international conference on RObotics and BIOmimetics/ Tianjin, China, 2010, pp. 685-690.

[11] Iqbal, J.; Tsagarakis, N. G.; Fiorilla, A. E.; Caldwell, D. G. Design requirements of a hand exoskeleton robotic device. $/ / 14^{\text {th }}$ IASTED International Conference on Robotics and Applications / Massachusetts, USA, 2009, pp. 44-51.

[12] Manzoor, S.; Islam, R. U.; Khalid, A.; Samad, A.; Iqbal, J. An open-source multi-DOF articulated robotic educational platform for autonomous object manipulation. Robotics and Computer Integrated Manufacturing. 30, 3 (2014), pp. 351362. DOI: 10.1016/j.rcim.2013.11.003

[13] Iqbal, J.; Riaz, S.; Khan, A.; Khan, H. A novel track-drive mobile robotic framework for conducting projects on robotics and control systems. // Life Sci J - Acta Zhengzhou University Overseas Edition. 10, 3(2013), pp. 130-137.

[14] Ahmad, O.; Ullah, I.; Iqbal, J. A multi-robot educational and research framework. // International Journal of Academic Research (IJAR) Part A, ISSN: 2075-4124 (print), 2075-7107 (online). 6, 2(2014), pp. 217-222.

[15] Iqbal, J.; Islam, R. U.; Khan, A. H. Modeling and analysis of a 6 DOF robotic arm manipulator. // Canadian Journal on Electrical and Electronics Engineering (CJEEE), ISSN: 1923-0540. 3, 6(2013), pp. 300-306.

[16] Ullah, M. I.; Ajwad, S. A.; Islam, R. U.; Iqbal, U.; Iqbal, J. Modeling and computed torque control of a 6 Degree of Freedom robotic arm. // IEEE International Conference on Robotics and Emerging Allied Technologies in Engineering / Islamabad, Pakistan, 2014, pp. 133-138. DOI: 10.1109/icreate.2014.6828353

[17] Ajwad, S. A.; Ullah, M. I.; Islam, R. U.; Iqbal J. Modeling robotic arms - A review and derivation of screw theory based kinematics. // International Conference on Engineering and Emerging Technologies / Lahore, Pakistan, 2014, pp. 98

[18] Zohaib, M.; Pasha, S. M.; Bushra, H.; Hassan, K.; Iqbal, J. Addressing collision avoidance and nonholonomic constraints of a wheeled robot: Modeling and simulation. // IEEE International Conference on Robotics and Emerging Allied Technologies in Engineering / Islamabad, Pakistan, 2014, pp. 306-311. DOI: 10.1109/icreate.2014.6828385

[19] Iqbal, J.; Tsagarakis, N. G.; Caldwell， D. G. Design optimization of ahand exoskeleton rehabilitation device. // Proceedings of RSS workshop on understanding the human hand for advancing robotic manipulation / Seattle USA, 2009, pp. 44-45.

[20] Iqbal, J.; Saad, M. R.; Tahir, A. M.; Malik, A. State estimation technique for a planetary robotic rover. // 
RevistaFacultad de Ingenieria-Universidad de Antioquia. 73(2014), pp. 58-68.

[21] Iqbal, J.; Pasha, M.; Riaz, S.; Khan, H.; Iqbal, J. Real-time target detection and tracking: A comparative in-depth review of strategies. // Life Sci J - Acta Zhengzhou University Overseas Edition. 10, 3(2013), pp. 804-813.

[22] Iqbal, J.; Pasha, S. M.; Khelifa, B.; Khan, A. A.; Iqbal, J. Computer vision inspired real-time autonomous moving target detection, tracking and locking. // Life Sci J ActaZhengzhou University Overseas Edition. 10, 4(2013), pp. 3338-3345.

[23] Iqbal, J.; Heikkila, S.; Halme, A. Tether tracking and control of ROSA robotic rover. $/ / 10^{\text {th }}$ IEEE International Conference on Control, Automation, Robotics and Vision / Hanoi, Vietnam, 2008, pp. 689-693. DOl: 10.1109/icarcv.2008.4795601

[24] Khan, A. A.; Riaz, S.; Iqbal, J. Surface estimation of a pedestrian walk for outdoor use of power wheelchair based robot. // Life Sci J - Acta Zhengzhou University Overseas Edition. 10, 3(2013), pp. 1697-1704.

[25] Zohaib, M.; Pasha, S. M.; Javaid, N.; Salaam, A.; Iqbal, J. An improved algorithm for collision avoidance in environments having $\mathrm{U}$ and $\mathrm{H}$ shaped obstacles. // Studies in Informatics and Control. 23, 1(2014), pp. 97-106.

[26] Zohaib, M.; Pasha, S. M.; Javaid, A.; Iqbal, J. IBA: Intelligent Bug Algorithm - A Novel Strategy to Navigate Mobile Robots Autonomously. // Emerging Trends and Applications in Information Communication Technologies, Communications in Computer and Information Science, Springer-Verlag Berlin Heidelberg. 414, (2014), pp. 291299. DOI: 10.1007/978-3-319-10987-9_27

[27] Jafri, S. R.; Iqbal, J.; Khan, H.; Chellali, R. A unified SLAM solution using partial 3D structure. // Elektronika \& Elektrotechnika (Journal of Electronics and Electrical Engineering). 20, 9 (2014), pp. 3-8.

[28] Azeem, M. M.; Iqbal, J.; Toivanen, P.; Samad, A. Emotions in robots. // Emerging Trends and Applications in Information Communication Technologies, Communications in Computer and Information Science (CCIS), Springer-Verlag Berlin Heidelberg. 281, (2012), pp. 144-153.

[29] Naveed, K.; Iqbal, J.; Rahman, H. U. Brain controlled human robot interface. // IEEE International Conference on Robotics and Artificial Intelligence / Islamabad, Pakistan, 2012, pp. 55-60. DOI: 10.1109/icrai.2012.6413410

[30] Islam, R. U.; Iqbal, J.; Manzoor. S.; Khalid A.; Khan, S. An autonomous image-guided robotic system simulating industrial applications. $/ / 7^{\text {th }}$ IEEE International Conference on System of Systems Engineering / Genova, Italy, 2012, pp. 344-349. DOI: 10.1109/sysose.2012.6384195

[31] Iqbal, U.; Samad, A; Nissa, Z.; Iqbal, J. Embedded control system for AUTAREP - A novel AUTonomous Articulated Robotic Educational Platform. // Tehnicki vjesnikTechnical Gazette. 21, 6(2014), pp. 1255-1261.

[32] Baizid, K.; Chellali, R.; Yousnadj, A.; Meddahi, A.; Iqbal J.; Bentaleb, T. Modelling of robotized site and simulation of robots optimum placement and orientation zone. // $21^{\text {st }}$ IASTED International Conference on Modelling and Simulation / Canada, 2010, pp. 9-16. DOl: 10.2316/p.2010.696-111

[33] Meddahi, A.; Baizid, K.; Yousnadj, A.; Iqbal, J. API based graphical simulation of robotized sites. $/ / 14^{\text {th }}$ IASTED International Conference on Robotics and Applications / Massachusetts USA, 2009, pp. 485-492.

[34] Smith, C. B. Robotic friction stir welding using a standard industrial robot. // Kei Kinzoku Yosetsu (Journal of Light Metal Welding and Construction). 42, 3 (2004), pp. 40-41.

[35] Patel, R.; Hedelind, M.; Villegas, P. L. Enabling robots in small-part assembly lines: The "ROSETTA approach" - an industrial perspective. // Proceedings of $7^{\text {th }}$ German Conference on Robotics / Munich, Germany. 2012.

[36] Yu, S.; Cao, L. Modeling and prediction of paint film deposition rate for robotic spray painting. // International Conference on Mechatronics and Automation /Beijing, China, 2011, pp. 1445-1450. DOI: 10.1109/icma.2011.5985963

[37] Dubey, V. N.; Dai, J. S. A packaging robot for complex cartons. // Industrial Robot: An International Journal. 33, 2 (2006), pp. 82-87.

[38] Qi, R.; Qian, H.; Lam, T. L. Xu, Y.; Zhang, T.; Zhu, W.; Zhang, F.; Liao, J. A new Cartesian cutting robot with laser height control system. // IEEE International Conference on Mechatronics and Automation / Beijing, China, 2011, pp. 2153-2158.

[39] Cortsen, J.; Jorgensen, J. A.; Solvason, D.; Petersen, H. G. Simulating robot handling of large scale deformable objects: Manufacturing of unique concrete reinforcement structures. // IEEE International Conference on In Robotics and Automation / Minnesota, USA, 2012, pp. 3771-3776. DOI: 10.1109/icra.2012.6225012

[40] Nagata, F.; Watanabe, K.; Kiguchi, K.; Tsuda, K.; Kawaguchi, S.; Noda, Y.; Komino, M. Joystick teaching system for polishing robots using fuzzy compliance control. // IEEE International Symposium on Computational Intelligence in Robotics and Automation / 2001, pp. 362367. DOI: $10.1109 /$ cira.2001.1013226

[41] Asfahl, C. R. Robots and manufacturing automation. 2nd edition, John Wiley \& Sons Inc., 1992.

[42] ABB Robotics. URL: http://new.abb.com/products/ robotics/industrial-robots/irb-7600. (22.07.2014).

[43] COMAU Robotics. URL: http://www.comau.com/eng/ offering_competence/robotics_automation/Pages/robotics_a utomation.aspx.(22.07.2014).

[44] Miller/Panasonic Robotics. URL: http://www.kcrobotics.com/new-robots/panasonic/. (22.07.2014).

[45] FANUC Robotics. URL: http://www.robots.com/pdfs/ robots/s-12-rj-or rj2_datasheet.pdf (22.07.2014).

[46] MOTOMAN Robotics. URL: http://www.motoman.com/ datasheets/SDA10D.pdf. (22.07.2014).

[47] Adept Robotics. URL: http://www.adept.com/products/ robots/6-axis/viper-s650/general. (22.07.2014).

[48] ABB Robotics. URL: http://new.abb.com/products/ robotics/industrial-robots. (22.07.2014).

[49] Kawasaki Robotics. URL: http://www.kawasakirobotics.com/Robots/KG264 Accessed: (22.07.2014).

[50] Islam, R. U.; Iqbal, J.; Khan, Q. Design and comparison of two control strategies for multi-DOF articulated robotic arm manipulator. // Control Engineering and Applied Informatics. 16, 2 (2014), pp. 28-39.

[51] Khan, M. F.; Islam, R. U.; Iqbal, J. Control strategies for robotic manipulators. // IEEE International Conference on Robotics and Artificial Intelligence / Islamabad, Pakistan, 2012, pp. 26-33. DOI: 10.1109/icrai.2012.6413422

[52] Zhang, X. The industrial manipulator control system based on programmable logic controller. // Applied Mechanics and Materials. 473 (2013), pp. 235-238. DOI: 10.4028/www.scientific.net/AMM.473.235

[53] Visioli, A. Research trends for PID controllers. // Acta Polytechnica. 52, 5(2012), pp. 144-150.

[54] Blevins, T. L. PID Advances in Industrial Control. // IFAC Conference on Advances in PID Control, Brescia, Italy, 2012. DOI: 10.3182/20120328-3-it-3014.00004

[55] McMillan, G. K. Industrial applications of PID control, PID control in the third millennium: Lessons learned and new approaches. Editors Ramon Vilanova and Antonio Visioli Springer, 2012, pp. 415-461. 
[56] Zhang, J.; Gao, X.; Li, E. An adaptive variable structure controller for robotic manipulators. $/ / 6^{\text {th }}$ International Forum on Strategic Technology. 2011 Vol. 1, pp. 351-355.

[57] Piltan, F.; Emamzadeh, S.; Hivand, Z.; Shahriyari, F.; Mirzaei, M. PUMA-560 robot manipulator position sliding mode control methods using MATLAB/SIMULINK and their integration into graduate/undergraduate nonlinear control, robotics and MATLAB courses. // International Journal of Robotic and Automation. 6, (2012), pp. 106-150.

[58] Mahayana, D.; Anwari, S. Robust adaptive control for robotic manipulator based on chattering free variable structure system. // IEEE International Conference on Electrical Engineering and Informatics / Selangor, Malaysia, 2012, pp. 247-252.

[59] Duan, S.; Chen, L.; Ma, Z.; Lu, G. Variable structure control with feed forward compensator for robot manipulators subject to load uncertainties. // IEEE International Conference on Control, Automation, Robotics and Vision. 2010, pp. 2367-2372.

[60] Rawaa, D. A. D.; Azeddien, K.; Saad, M.; Mohd, S. B.; Shahaboddin, S. System identification and control of robot manipulator based on fuzzy adaptive differential evolution algorithm. // Advances in Engineering Software. 78, (2014), pp. 60-66. DOI: 10.1016/j.advengsoft.2014.08.009

[61] Chaudhary, H.; Parashar, A.; Prasad, R.; Sukavanam, N. Velocity observer based fuzzy $\mathrm{PD}+\mathrm{I}$ based hybrid force/position control of an industrial robot. // IEEE Conference on Recent Advanced in Engineering and Computational Sciences / Chandigarh, India, 2014, pp. 1-6. DOI: 10.1109/raecs.2014.6799648

[62] Zacharia, P. T.; Xidias, E. K.; Aspragathos, N. A. Task scheduling and motion planning for an industrial manipulator. // Robotics and Computer-Integrated Manufacturing. 29, (2013), pp. 449-462. DOI: 10.1016/j.rcim.2013.05.002

\section{Authors' addresses}

Assist. Professor Dr. Jamshed Iqbal, PhD, MSc

Department of Electrical Engineering,

COMSATS Institute of Information Technology (CIIT),

Park Road, Chak Shahzad, Islamabad, Pakistan

Corresponding author: jamshed.iqbal@comsats.edu.pk

Raza Ul Islam, MSc

Center of Advance Studies in Telecommunication (CAST),

COMSATS Institute of Information Technology (CIIT),

Park Road, Chak Shahzad,

Islamabad, Pakistan

Syed Zain Abbas, BSc

Department of Electrical Engineering,

COMSATS Institute of Information Technology (CIIT),

Park Road, Chak Shahzad, Islamabad, Pakistan

Abdul Attayyab Khan, MSc

Dipartimento di Informatiche, Bioingegneria,

Robotica e IngegneriadeiSistemi (DIBRIS),

University of Genova, Genova, Italy

\section{Syed Ali Ajwad, MSC}

Department of Electrical Engineering,

COMSATS Institute of Information Technology (CIIT),

Park Road, Chak Shahzad, Islamabad, Pakistan 